\title{
Erratum to: Crustal structure and deformation associated with seamount subduction at the north Manila Trench represented by analog and gravity modeling
}

\author{
Fucheng Li • Zhen Sun • Dengke Hu •
}

Zhangwen Wang

Published online: 5 March 2014

(C) Springer Science+Business Media Dordrecht 2014

\section{Erratum to: Mar Geophys Res 34:393-406 (2013) \\ DOI 10.1007/s11001-013-9193-5}

In Figure 4, Figure 5 and Figure 6 caption of the abovementioned article, the citations were wrongly omitted.

The full Figure 4 caption should be "Fig. 4 a Seismic interpretation of MCS693-4; b seismic interpretation of MSC693-6 with considerable flat basement. The original seismic profiles are from Ku and Hsu (2009)".

The full Figure 5 caption should be "Fig. 5 Sketch charts of $\mathbf{a}$ the active margin zone. $\mathbf{b}$ The experimental setup of this study. The sketch chart of the active margin zone is modified from Pedley (2010) in references to the research of Moore (1988); Von and Scholl (1993); Dominguez et al. (1998)".

The full Figure 6 caption should be "Fig. 6 a Sketch chart shows the position of the subducting seamount at different stages $(\mathbf{b}, \mathbf{c}, \mathbf{d})$. $\mathbf{b}-\mathbf{d}$ Results and interpretation of seamount subduction, the positions correspond to $\mathbf{b}$, $\mathbf{c}$, and $\mathbf{d}$ in $\mathbf{a}$. The red in Part (d) shows the position of a crosssection made in Fig. 7. The plan views are modified after $\mathrm{Li}$ et al. (2012)".

The authors regret any inconvenience caused.

The online version of the original article can be found under doi:10. 1007/s11001-013-9193-5.

F. Li $\cdot$ Z. Sun $(\bowtie) \cdot$ Z. Wang

Key Laboratory of Marginal Sea Geology, Chinese Academy of

Sciences, Guangzhou, 510301, China

e-mail: zhensun@scsio.ac.cn

\section{F. Li $\cdot$ Z. Wang}

University of Chinese Academy of Sciences, Beijing 100049,

China

D. $\mathrm{Hu}$

School of Geosciences, University of Aberdeen,

Aberdeen AB243UE, UK 